Journal of Animal and Veterinary Advances 10 (3): 334-340, 2011

ISSN: $1680-5593$

(C) Medwell Journals, 2011

\title{
Consumer's Willingness to Pay for Organic Chicken Meat in Samsun Province of Turkey
}

\author{
${ }^{1}$ Orhan Gunduz and ${ }^{2}$ Zeki Bayramoglu \\ ${ }^{1}$ Department of Agricultural Economics, Faculty of Agriculture, \\ Ondokuz Mayis University, Samsun, Turkey \\ ${ }^{2}$ Department of Agricultural Economics, Faculty of Agriculture, \\ Selcuk University, Konya Turkey
}

\begin{abstract}
The study aimed to determine consumers willingness to pay extra money for organically raised chicken meat rather than conventionally raised chicken meat. Research data was collected from randomly selected 150 households in Samsun province by using contingent valuation survey method. We used an ordered probit approach for identifying consumer characteristics and attitudes that influence the WTP for organically raised chicken meat. Research results revealed that $81 \%$ of the respondents would be willing to pay a premium for organically raised chicken meat. The ordered probit model results showed that willingness to pay was mainly related to tree socio-economic factors which are monthly household income, education level of household head and monthly conventionally raised chicken meat consumption together with 2 attitude factors which are whether previously organic food consumption in the household and respondents opinion about risks of conventionally raised chicken meat to human health. These factors were statistically significant and had positive effect on the WTP.
\end{abstract}

Key words: Consumption, willingness to pay, ordered probit, organic, Samsun, Turkey

\section{INTRODUCTION}

In the last five decades, there has been growing concern about food safety and quality. Sustainable safe and quality food production and consumption is one of the major issues of the 21 st century. Consumers concerns about food are focused on worries not only about health but also about agriculture, ecology and food culture.

Health and environmental protection issues have become popular in the world and elsewhere and the demand for organic foods has grown rapidly since the mid 1980s in many countries (Davis et al., 1995; Greenan et al., 1997; Boccaletti and Nardella, 2000; Corsi and Novelli, 2002; Akgungor et al., 2007; Dipeolu et al., 2009).

Organic food is produced without using most conventional pesticides, fertilizers made with synthetic ingredients or sewage sludge, bioengineering or ionizing radiation (Shaharudin et al., 2010). Success with organic foods depends on consumer acceptance and use (Briz and Ward, 2009). Demand for organic foods has increased considerably during the past decade, though organic consumption still only constitutes a few per thousand of total food consumption in Turkey. Often, the high prices and poor supply of organic products seem to be the major constraint for organic food consumption. Turkey's organic production started in mid $1980 \mathrm{~s}$. The first production and exports were limited raisins and dried figs (Akgungor et al., 2007). Nowadays, Turkey produced almost 250 organic food items. Yet, organic food of animal origin has not been produced in Turkey.

Chicken meat has become a popular food for most people because it is considered to be a healthy and low price option. In 1990 s, chicken meat consumption was rapidly growing mainly due to low price and healthy in Turkey. But a series of food scares the overuse of antibiotics, growth promoters and other chemicals and $\mathrm{H} 5 \mathrm{~N} 1$ (Avian Influenza) as known bird flu, increase consumers concerns on chicken meat consumption (Lacaze et al., 2009). Whereas organic chicken is different from the ordinary chicken as the breeding and growth require natural way technique rather than the use of substance, vaccine and chemical to reduce the chicken maturity age. The meats of organic chicken are high in protein comparing to non organic one which promotes antioxidant and anticancer to those who consume it (Shaharudin et al., 2010). Turkey has a great potential of organic chicken meat and other organic products. Consumption of ordinary chicken meat was $15.7 \mathrm{~kg}$ per

Corresponding Author: Orhan Gunduz, Department of Agricultural Economics, Faculty of Agriculture, Ondokuz Mayis University, Samsun, Turkey 
capita in 2008 in Turkey. Presently in Turkey however, organic chicken meat production and consumption market did not exist.

Aryal et al. (2009) reported that production and marketing strategies of organic products are determined considering the willingness to pay a premium price. For further betterment of management more detailed studies are needed in understanding the perception of people about organic foods. It is also important to understand how willing people are to pay more price for organic products. Up to the present, many researchers have calculated consumers willingness to more pay for organic foods (Govindasamy and Italia, 1999; Fu et al., 1999; Boccaletti and Nardella, 2000; Corsi and Novelli, 2002; Engel, 2008; Aryal et al., 2009; Dipeolu et al., 2009; Kalogeras et al., 2009; Lacaze et al., 2009; Shaharudin et al., 2010). However, similar studies were very rare in Turkey (Budak et al., 2006; Akgungor et al., 2007). It was coincided that there is a research on the consumer preferences for organic chicken meat made by Armagan and Ozdogan (2005).

Therefore, the purposes of the study were to determinate consumers willingness to more pay for organically raised chicken meat and to explore socioeconomic and attitude factors influencing consumers WTP. In the study, it is believed that the results may provide some useful important information to promote organic chicken meat production and consumption. The research results will provide to the retailers important information about the main socio-economic factors affecting consumers organic food consumption decisions.

\section{MATERIALS AND METHODS}

The data applied in this study were collected through a Contingent Valuation (CV) survey in May-June 2010. The sample size was determined to be 150 using Eq. 1 (Collins, 1986):

$$
\begin{aligned}
& \mathrm{n}=\frac{\mathrm{t}^{2 *} \mathrm{p}^{*} \mathrm{q}}{\mathrm{E}^{2}} \\
& \mathrm{n}=\frac{1.96^{2} * 0.50 * 0.50}{0.08^{2}}=150
\end{aligned}
$$

Where:

$\mathrm{n}=$ The sample size

$\mathrm{t}=$ The 95\% significance level (1.96)

$\mathrm{p}=$ The probability of the situation being searched (it is assumed to be $50 \%$ )

$\mathrm{q}=1-\mathrm{p}$ and $\mathrm{E}$ is the accepted error (assumed to be $8 \%$ )

The questionnaire used in the study was composed into the 2 parts. In the first part of the questionnaire, about 8 socio-economic and 2 attitude characteristics of consumers were measured. The socio-economic characteristics are age, gender and education level of respondent, monthly household income, household size, household with children $<14$ years of age and monthly household chicken meat consumption. First attitude characteristic is respondents opinion about the risks of conventionally raised chicken meat on human health while second is situation of respondents chicken meat consumption, previously.

If respondents think that non-organic raised products have a risk on the human health, first attitude variable is equal to 1 otherwise 0 . If the respondents consumed the organic foods, previously, second variable is equal to 1 , otherwise 0 .

In the second part of questionnaire, consumers willingness to pay for organically raised chicken meat was examined. After providing information on organic chicken meat, respondents were asked to indicate how much more than the regular price of non-organic raised chicken meat, if any they would pay for organically raised chicken meat.

Consumers WTP for organic chicken meat was considered as dependent variable in the research. Respondents were posed with the following WTP question: Suppose your favorite purchased chicken meat has a price premium. Assuming no difference in taste and nutritional content would you pay slightly more for a pesticide free and organically raised version of the same chicken meat?

In the research, Contingent Valuation (CV) method which was formed by Hanemann (1984) was used to examine the determinants of consumers willingness to pay for organically raised chicken meat. $\mathrm{CV}$ is the most commonly used non-market valuation technique for environmental goods because of its flexibility (Carson et al., 2001).

$\mathrm{CV}$ allows a direct estimation of Willingness To Pay (WTP) by means of different (direct) elicitation techniques. WTP elicitation using a payment card method is appropriate for its simplicity and to give to basically uninformed individuals a detailed choice among a range of predefined price premiums.

This method asks respondents to select the amount they are willing to pay from a checklist of possible payments either in absolute terms or as a percentage of prices (Boccaletti and Nardella, 2000; Lacaze et al., 2009). In the study, payment card method was chosen to elicit consumers willingness to more pay from four classes of premium prices (Fig. 1). Those classes were collected as following: 


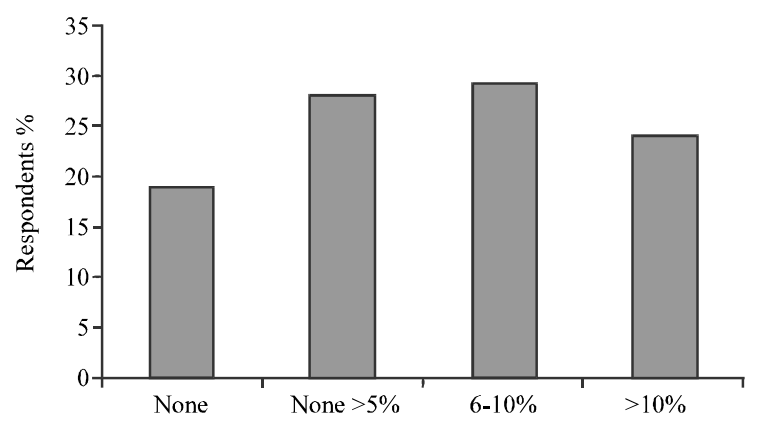

Fig. 1: Respondents WTP

- $\quad$ No $(0 \%)(\mathrm{WTP}=0)$

- Yes, I would pay between 1 and $5 \%$ more for the organic chicken meat $($ WTP $=1)$

- Yes, I would pay between 6 and $1 \% 0$ more for the organic chicken meat (WTP $=2)$

- Yes, I would pay between $>10 \%$ for the organic chicken meat $(\mathrm{WTP}=3)$

Since the WTP dependent variable is expressed ordinal ranking, ordered probit model was developed to calculate the parameters estimates of WTP for organic chicken meat consumption. The ordered probit model is specified on the assumption that the consumer's response to the willingness to pay question depends around a latent variable such as (Green, 2000):

$$
\mathrm{WTP}^{*}=\beta \mathrm{x}+\varepsilon, \quad \varepsilon \sim \mathrm{N}[0.1]
$$

Where:

WTP $^{*}=$ An unobserved willingness to pay

$\mathrm{x}=\mathrm{A}$ vector of independent variables thought to influence WTP

$\beta=\mathrm{A}$ vector of parameters reflecting the relationship between willingness-to-pay and variables in $\mathrm{x}$

$\varepsilon \quad=$ An independently and identically distributed error term with mean zero and variance one

The relationship between WTP $^{*}$ and the observed variable WTP is assumed to be a function of cut-off points $\left(\mu_{\mathrm{j}}\right)$ which are estimated along with the regression coefficients and vary with individuals. Assume a consumer's WTP choice is one of the four alternatives $(y=0,1,2,3)$ discussed earlier follow (Green, 2000):

$$
\left\{\begin{array}{ll}
\text { If } \text { WTP }^{*} \leq 0 & y=0 \\
\text { If } 0<\text { WTP }^{*} \leq \mu_{1} & y=1 \\
\text { If } \mu_{1}<\text { WTP }^{*} \leq \mu_{2} & y=2 \\
\text { If } \mu_{2} \leq \text { WTP }^{*} & y=3
\end{array}\right\}
$$

Where, $\mu_{1}$ and $\mu_{2}\left(0<\mu_{1}<\mu_{2}\right)$ are unknown threshold parameters of $y^{*}$ to be estimated with $\beta$. Since the random error term is assumed to be distributed standard normal, the probabilities of a consumer's willingness to pay response in a specific category can be expressed as follows (Green, 2000):

$$
\left\{\begin{array}{l}
\operatorname{Prob}(\mathrm{WTP}=0)=\phi\left(-\beta^{\prime} \mathrm{x}\right) \\
\operatorname{Prob}(\mathrm{WTP}=1)=\phi\left(\mu_{1}-\beta^{\prime} \mathrm{x}\right)-\phi\left(-\beta^{\prime} \mathrm{X}\right) \\
\operatorname{Prob}(\mathrm{WTP}=2)=\phi\left(\mu_{2}-\beta^{\prime} \mathrm{x}\right)-\phi\left(\mu_{1}-\beta^{\prime} \mathrm{X}\right) \\
\operatorname{Prob}(\mathrm{WTP}=3)=1-\phi\left(\mu_{2}-\beta^{\prime} \mathrm{X}\right)
\end{array}\right\}
$$

Where, $\Phi($.$) is the cumulative probability function of$ a normal distribution for the range of consumer's utility. Using this structure and a sample of $\mathrm{n}$ observations, the $\log$ likelihood function is developed and maximized with respect to $\beta, \mu_{1}, \mu_{2}$ in order to obtain the ordered probit MLEs $\hat{\beta}, \hat{\mu}_{1}, \hat{\mu}_{2}$, respectively.

The interpretation of the estimated coefficients of the ordered probit is a little tricky. The signs of parameter estimates and their statistical significance indicate the direction of the response associated with the presence or level of a particular variable. The changes in the probabilities associated to the intermediate categories ( 1 to $\mathrm{j}-1$ ) cannot be signed a priori. Thus, categoryspecific marginal effects are often reported. For the ordered probit model, the marginal effects of variable on the probability of a consumer making each of four possible choices can be computed from estimated coefficients by following expression (Green, 2000):

$$
\begin{aligned}
& \frac{\partial \mathrm{P}(\mathrm{WTP}=0)}{\partial \mathrm{x}_{\mathrm{k}}}=-\phi\left(\beta^{\prime} \mathrm{x}\right) \beta \\
& (\partial \mathrm{P}(\mathrm{WTP}=1)) / \partial \mathrm{x}_{\downarrow} \mathrm{k}=\left\{\phi\left(-\beta^{\uparrow^{\prime}} \mathrm{x}\right)-\phi\left(\mu_{\downarrow} 1-\beta^{{ }^{\prime}} \mathrm{x}\right)\right\} \beta \\
& (\partial \mathrm{P}(\mathrm{WTP}=2)) / \partial \mathrm{x}_{\downarrow} \mathrm{k}=\left\{\phi\left(\mu_{\downarrow} 1-\beta^{\uparrow^{\prime} \mathrm{x}}\right)-\phi\left(\mu_{\downarrow} 2-\beta^{\uparrow^{\prime}} \mathrm{x}\right)\right\} \beta \\
& \frac{(\partial \mathrm{P}(\mathrm{WTP}=3)}{\partial \mathrm{x}_{\mathrm{k}}}=\phi\left(\mu_{2}-\beta^{\prime} \mathrm{x}\right) \beta
\end{aligned}
$$

Where:

$\frac{\partial \mathrm{P}}{\partial \mathrm{x}_{\mathrm{k}}} \quad=$ The derivative of probability with respect to

$\mathrm{x}_{\mathrm{k}}, \Phi()=$. The cumulative probability function

$\beta=$ The ordered Probit MLE of $\mathrm{x}_{\mathrm{k}}$ 's parameters

The marginal effects should sum to zero by canceling one another out across the response categories. Interpretation of the marginal effects is straight forward assuming all other things are equal, a unit change in the explanatory variable will result increase or decrease in 
particular ranking in the predicted probability equal to the size of the marginal effect. Overall probabilities were calculated at the variables mean values using estimated intercepts and coefficients. Significance of the model was verified by calculating the $\chi^{2}$ statistics resulting from the restricted log-likelihood functions.

\section{RESULTS AND DISCUSSION}

The purpose of the estimated model was to measure the impact of the most relevant explanatory factors on the consumer WTP with regards to organically raised chicken meat. A description of the dependent and explanatory variables used in the ordered probit model was shown in Table 1 .

Except for the household size, all explanatory variables were binary (i.e., either zero or one). For each group of variables, the dropped variable was selected randomly. Nevertheless, interpretation of results was relative to the dropped variable for that category of question.

According to the survey results, average household size of the respondents was 3 persons, average monthly household income was $1750 \mathrm{TL}$ and most of respondents in $\mathrm{NNC} 2$ income group. Average age of consumers was 39. The male respondents constituted $56 \%$ of total respondents while that of females was $44 \%$. The survey results also revealed that $44 \%$ of respondents concerned about the risks of non-organic foods on human health.

Most of respondents were willing to pay more than by $6-10 \%$ as a price premium for organically raised chicken meat (Table 1).

Figure 1 shows range of possible WTP categories and percentage distribution of responses. The survey clearly suggests that $19 \%$ of respondents were not willing to pay a price premium for organically raised chicken meat while $28 \%$ of respondents were willing to pay a premium price $<5,29 \%$ of respondents were willing to pay premium price between 6 and1 $0 \%, 24 \%$ were willing to pay a premium price $>10 \%$ of the regular price.

Estimated parameters of the ordered probit model were shown in Table 2. INC1, AGE1, EDU1 and CONS1 variables were dropped in the model in order to avoid multicollinearity problem among explanatory variables. The ordered probit model was statistically significant with a likelihood ratio test probability of $<0.0001$. The overall ability of the model to predict the respondent's actual choice of willingness to pay correctly was $41 \%$.

Table 1: Descriptive and summary statistics of explanatory variables used in the ordered probit model

\begin{tabular}{|c|c|c|c|c|c|}
\hline Variables definition & Code & Min. & Max. & Mean & SD \\
\hline \multicolumn{6}{|l|}{$\overline{\text { Explanatory variables }}$} \\
\hline \multicolumn{6}{|l|}{ Socio-economic variables } \\
\hline Household size (person) & HSIZE & 1 & 6 & 3.35 & 1.24 \\
\hline \multicolumn{6}{|l|}{ Hous ehold monthly income (TL) ${ }^{*}$} \\
\hline$<1000 \mathrm{TL}=1$; otherwise $=0$ & $\mathrm{NNC1}^{\mathrm{a}}$ & 0 & 1 & 0.22 & 0.42 \\
\hline $1000 \mathrm{TL}-1999 \mathrm{TL}=1$; otherwise $=0$ & $\mathrm{INC} 2$ & 0 & 1 & 0.46 & 0.50 \\
\hline$>2000 \mathrm{TL}=1 ;$ otherwise $=0$ & $\mathrm{INC3}$ & 0 & 1 & 0.32 & 0.47 \\
\hline \multicolumn{6}{|l|}{ Have household children $<14$ years old? } \\
\hline Yes $=1 ;$ No $=0$ & CHILD & 0 & 1 & 0.40 & 0.49 \\
\hline \multicolumn{6}{|l|}{ Gender of respondent } \\
\hline Male $=1 ;$ Female $=0$ & GENDER & 0 & 1 & 0.56 & 0.50 \\
\hline \multicolumn{6}{|l|}{ Education level of respondent } \\
\hline Elementary school or less $=1$; otherwise $=0$ & EDU1 $^{\mathrm{a}}$ & 0 & 1 & 0.30 & 0.46 \\
\hline Secondary or high school $=1$; otherwise $=0$ & EDU2 & 0 & 1 & 0.39 & 0.49 \\
\hline University $=1$; otherwise $=0$ & EDU3 & 0 & 1 & 0.31 & 0.46 \\
\hline \multicolumn{6}{|l|}{ Age of respondent (year) } \\
\hline$<30=1 ;$ otherwise $=0$ & $\mathrm{AGE}^{\mathrm{a}}$ & 0 & 1 & 0.18 & 0.39 \\
\hline $30-44=1 ;$ otherwise $=0$ & AGE2 & 0 & 1 & 0.51 & 0.50 \\
\hline$>44=1 ;$ otherwise $=0$ & AGE3 & 0 & 1 & 0.31 & 0.47 \\
\hline \multicolumn{6}{|c|}{ Hous ehold monthly chicken meat consumption (kg) } \\
\hline No consumption $=1$; otherwise $=0$ & CONS1 $1^{\mathrm{a}}$ & 0 & 1 & 0.21 & 0.41 \\
\hline $1-3=1 ;$ otherwise $=0$ & CONS2 & 0 & 1 & 0.45 & 0.50 \\
\hline$>3=1 ;$ otherwise $=0$ & CONS3 & 0 & 1 & 0.34 & 0.48 \\
\hline \multicolumn{6}{|l|}{ Attitude variables } \\
\hline \multicolumn{6}{|c|}{ Has respondent previously consumed organic food products? } \\
\hline Yes $=1 ;$ No $=0$ & PRECONS & 0 & 1 & 0.07 & 0.26 \\
\hline \multicolumn{6}{|l|}{ Risk } \\
\hline \multicolumn{6}{|l|}{ If respondents think that non-organic products have } \\
\hline a risk on the human health $=1$, otherwise $=0$ & RISK & 0 & 1 & 0.44 & 0.50 \\
\hline \multicolumn{6}{|l|}{ Dependent variable } \\
\hline None $=0,<5=1,6-10 \%=2,>10 \%=3$ & WTP & 0 & 3 & 1.59 & 1.05 \\
\hline
\end{tabular}


Table 2: Estimates of the ordered probit model for consumers WTP for organic chicken meat

\begin{tabular}{lccrr}
\hline Variables & Coefficient & SE & t-stat & $p$ values \\
\hline Constant & $-0.9689^{* *}$ & 0.3793 & -2.5540 & 0.0106 \\
HSIZE & 0.1203 & 0.1275 & 0.9440 & 0.3453 \\
INC2 & $0.4936^{* * * *}$ & 0.2952 & 1.6720 & 0.0946 \\
INC3 & $1.2070^{* *}$ & 0.3904 & 3.0920 & 0.0020 \\
CHILD & 0.2399 & 0.2563 & 0.9360 & 0.3493 \\
GENDER & 0.2136 & 0.2133 & 1.0020 & 0.3165 \\
EDU2 & 0.3242 & 0.2425 & 1.3370 & 0.1813 \\
EDU3 & $1.1051^{*}$ & 0.2984 & 3.7040 & 0.0002 \\
AGE2 & -0.3474 & 0.3405 & -1.0200 & 0.3076 \\
AGE3 & 0.0060 & 0.4067 & 0.0150 & 0.9882 \\
CONS2 & $0.5407^{* * * *}$ & 0.2783 & 1.9430 & 0.0521 \\
CONS3 & $0.7121^{* *}$ & 0.3398 & 2.0960 & 0.0361 \\
PRECONS & $1.4881^{* *}$ & 0.6304 & 2.3600 & 0.0183 \\
RISK & $0.4790^{* * *}$ & 0.2120 & 2.2590 & 0.0239 \\
$\mu_{1}$ & $1.2297^{* *}$ & 0.1835 & 6.7020 & 0.0000 \\
$\mu_{2}$ & $2.3689^{* *}$ & 0.2108 & 11.2350 & 0.0000 \\
\hline
\end{tabular}

$*, * *$ and $* * *$ indicates that statistically significant at the $0.01,0.05$ and 0.10 level, respectively. Likelihood ratio test $=\chi^{2}: 95.79, \mathrm{p}<0.000$

Table 2 also shows the estimates of the threshold variables. These are interpreted as the numerical linkages between the utility function of each respondent and their WTP for organic chicken meat. According to Maddala (1983), the threshold coefficients must be positive and should exhibit the relationship $\mu_{1}<\mu_{2}$.

The estimated threshold parameters were all positive and statistically significant at the $1 \%$ confidence level, suggesting that response categories are indeed ordered properly. Thus, the socio-economic factors and consumers attitudes variables in the ordered model equation are relevant in explaining of the consumers WTP for organic chicken meat. About 5 of the 11 socioeconomic and 2 attitudes variables are statistically significant.

The estimated parameters of the explanatory variables $\mathbb{N C} 2$, INC3, EDU3, CONS2, CONS3, PRECONS and RISK were positive signs and statistically significant. HSIZE, CHILD, GENDER, EDU2, AGE2 and AGE3 variables were statistically insignificant $(p>0.10)$ and had positive signs except AGE2.

The sign of coefficient statistically insignificant variables suggested that the WTP a premium price for organic chicken meat increased with HSIZE, CHILD, GENDER, EDU2, AGE2 and AGE3 variables. Household income level was important variable influencing WTP. As household income increases probability of WTP for organic chicken meat is also increasing. Estimated coefficients of $\mathrm{NNC} 2(0.49)$ increase as income increased through the highest income category of $\mathrm{NNC3}$ (1.21). This finding confirmed the results of many previous studies. These studies suggested that relation between income and WTP was positive and statistically significant.
(Govindasamy and Italia, 1999; Boccaletti and Nardella, 2000; Akgungor et al., 2007; Budak et al., 2006; Senturk, 2009). Education was only significant for the university educated respondents (EDU3) variable in the study. Estimated coefficient for EDU3 is positive and significant at the $99 \%$ level of confidence.

This research revealed that educational level of household head had positive effect on WTP. This is consistent with the results of Du Toit and Crafford (2003), Budak et al. (2006) and Senturk (2009) which emphasized that higher levels of education increased the probability of purchasing organic food. However, Boccaletti and Nardella (2000) was reported different result. They estimated that the household income negatively influences the probability of WTP.

Research results also showed that there was a positive relationship between the WTP for organic chicken meat and monthly household chicken meat consumption. Estimated coefficients for household chicken meat consumption belong CONS2 and CONS3 were positive and statistically significant at 90 and $95 \%$ level of confidence, respectively. Higher monthly chicken meat consumed respondents seem to be more WTP for organically raised chicken meat comparing to others. One of the reasons of the positive relationship between CONS variables and the WTP might be assuming that the chicken meat was very healthy. Similarly, Budak et al. (2006) reported that relation between conventionally raised seafood consumption and WTP for organic seafood was statistically significant and had positive sign.

Coefficient of first attitude variable (PRECONS) was positive sign and statistically significant indicating that there was a positive relationship between the probability of paying a premium greater than of the regular price and PRECONS.

It meant that consumers organic food consumption increases caused to increase the probability of WTP for organically raised chicken meat. Cranfield and Magnusson (2003) reported similar results. They revealed that the sign of PRECONS variable was positive but statistically insignificant.

Health issues are also considered important influencing factors on the WTP for organic food consumption. For example, news about Avian Influenza (H5N1) disease, commonly known as bird flu affected the sale of chicken meat products. According to the results of the model, second attitude variable (RISK) had a positive sign and was statistically significant at $95 \%$ confidence level indicating that concerning about food safety issues 
Table 3: Estimated marginal probabilities

\begin{tabular}{lcccc}
\hline Variables & $\begin{array}{c}\text { Prob } \\
(\text { WTP }=0)\end{array}$ & $\begin{array}{c}\text { Prob } \\
(\text { WTP }=1)\end{array}$ & $\begin{array}{c}\text { Prob } \\
(\text { WTP }=2)\end{array}$ & $\begin{array}{c}\text { Prob } \\
(\text { WTP }=3)\end{array}$ \\
\hline HSIZE & -0.0191 & -0.0285 & 0.0188 & 0.0288 \\
INC2 & -0.0782 & -0.1171 & 0.0770 & 0.1183 \\
INC3 & -0.1912 & -0.2863 & 0.1883 & 0.2892 \\
CHILD & -0.0380 & -0.0569 & 0.0374 & 0.0575 \\
GENDER & -0.0338 & -0.0507 & 0.0333 & 0.0512 \\
EDU2 & -0.0513 & -0.0769 & 0.0506 & 0.0776 \\
EDU3 & -0.1750 & -0.2621 & 0.1724 & 0.2647 \\
AGE2 & 0.0550 & 0.0824 & -0.0542 & -0.0832 \\
AGE3 & -0.0010 & -0.0014 & 0.0009 & 0.0015 \\
CONS2 & -0.0856 & -0.1283 & 0.0843 & 0.1296 \\
CONS3 & -0.1128 & -0.1689 & 0.1111 & 0.1706 \\
PRECONS & -0.2357 & -0.3530 & 0.2321 & 0.3566 \\
RISK & -0.0759 & -0.1136 & 0.0747 & 0.1148 \\
\hline
\end{tabular}

increased the consumption and WTP for organic food products. This result confirmed the results of Budak et al. (2006).

Marginal effects of explanatory variables on WTP probabilities were shown in Table 3 . The marginal effect of INC3 on the WTP a premium price for organically raised chicken meat suggested that if the respondent is in the INC3 income category, there were an increase by $29 \%$ in the probability of choosing WTP $=3$, an increase by $19 \%$ in the probability of choosing WTP $=2$, an decrease by $29 \%$ in the probability of choosing WTP $=1$ and a decrease by $19 \%$ in the probability of choosing None WTP for organic chicken meat. The probabilities of choosing WTP = 3 increase by 12 and $29 \%$, respectively as household income category changes from $\mathrm{INC} 2$ to the INC3 category. It was clear based on these findings that if monthly household income increased, WTP for organic chicken meat would increase.

Based on the value of marginal effects belong to EDU3 on the WTP for organic chicken meat, a unit increase of educated respondents who had university degree led to increase in the probability of WTP a higher premium for organic chicken meat.

The marginal effect of monthly household chicken meat consumption categories (CONS2 and CONS3) suggested that an increase in the conventionally raised chicken meat consumption led to decrease in the probability of WTP $=0$ for organic chicken meat by 0.09 and 0.11 for two categories while probability of WTP $=3$ increased by 0.13 and 0.17 .

Research results revealed that PRECONS variable strongly affected the consumers decisions about probability of WTP for organic chicken meat. An increase in the respondents who previously consumed organic products, increases the probability of $\mathrm{WTP}=3$ for organic chicken meat by 0.36 however, decreases the probability of WTP $=0$ by 0.24 . RISK attitude variable also affected the consumer decisions. Respondents who concern about food safety and health consumed more organic foods.
The marginal effect of RISK on the WTP a premium price for organically raised chicken meat indicated that an increase in the RISK variable caused the increase by $11 \%$ in the probability of choosing WTP $=3$, an increase by $7 \%$ in the probability of choosing WTP $=2$, decrease by $1 \%$ in the probability of choosing WTP $=1$ and decrease by $7 \%$ in the probability of choosing none WTP for organic chicken meat.

\section{CONCLUSION}

In recent years, rising consumer concerns about foodborne diseases such as avian influenza, mad cow and brucellosis has rapidly increased to demand for organic foods. Consumers even willing to pay for organically raised foods. However, organic food production and supply is not at expected levels in many countries as well as Turkey. High prices and poor supply of organic products seem to be the major constraint for organic food consumption. Presently in Turkey, organic chicken meat production and consumption market did not exist. However, Turkey with a population of 72 million has a great potential of organic chicken meat and other organic products.

For further determination of WTP for organic foods demand, need more detailed scientific studies in understanding the perception of consumers. The identification of consumer characteristics that influence the probability of WTP for organic food will be valuable as the market continues its growth.

This study was aimed to measure the socio-economic and attitude factors influencing consumers willingness to pay for organically raised chicken meat more than regular price of conventionally raised chicken meat. The research result indicated that $81 \%$ of the respondents would be willing to pay a premium for organically raised chicken meat. The result represents that consumers' WTP and potential demand was quite high. Thus, organic chicken meat might gain an appreciable market share in Turkey.

The results of probit model reveal that from all the factors hypothesized to positively influence consumers WTP except AGE2 factor. However, monthly income of household variables ( $\mathrm{NNC2}, \mathrm{INC} 3$ ), education of household head (EDU3), monthly household conventional chicken meat consumption variables (CONS2, CONS3), PRECONS and RISK variables were found to be basic factors influencing consumers WTP for organically raised chicken meat.

In regard to the consumers attitude variable (RISK) was strongly impact on consumers WTP for organically raised chicken meat. Health issue such as news about 
Avian influenza is also considered important determiners of the changing trends in the WTP for organic chicken meat. According to the results of this study, RISK variable had the most significant explanatory variable among the attribute specific variables.

The major contribution of this study is to provide new insights for identifying market strategies and policy implications for the organic food sector especially organic chicken meat. Marketing strategies of organic foods in Turkey should focus on not only socio-economic characteristics of household but also health issues.

\section{REFERENCES}

Akgungor, S., B. Miran and C. Abay, 2007. Consumer willingness to pay for organic products in urban Turkey. Proceedings of the 105th EAAE Seminar on International Marketing and International Trade of Quality Food Products, March 8-10, Italy, pp: 481-491.

Armagan, G. and M. Ozdogan, 2005. Consumption patterns of ecological egg and chicken meat and determining the consumer preferences. J. Anim. Prod., 46: 14-21.

Aryal, K.P., P. Chaudhary, S. Pandit and G. Sharma, 2009. Consumers' willingness to pay for organic products: A case from Kathmandu Valley. J. Agric. Environ., 10: $15-26$.

Boccaletti, S. and M. Nardella, 2000. Consumer willingness to pay for pesticide-free fresh fruit and vegetables in Italy. Int. Food Agribus. Manage. Rev., 3: $297-310$.

Briz, T. and R.W. Ward, 2009. Consumer awareness of organic products in Spain: An application of multinominal logit models. Food Policy, 34: 295-304.

Budak, F., D.B. Budak, O.O. Kacira and M.C. Yavuz, 2006. Consumer willingness to pay for organic sea bass in Turkey. Isr. J. Aquacult. Bamidgeh, 58: 116-123.

Carson, R.T., N.E. Flores and N.F. Meade, 2001. Contingent valuation: Controversies and evidence. Environ. Resour. Econ., 19: 173-210.

Collins, M., 1986. Sampling. In: Consumer Market Research Handbook, Worcester, R.M. and J. Downham (Eds.). McGraw-Hill, London.

Corsi, A. and S. Novelli, 2002. Consumers willingness to pay a price for organic beef meat. 10th EAAE Congress, August 28-31, Zaragoza-Spain. http://ideas.repec.org/p/ags/eaae02/24923.html.

Cranfield, J.A.L. and E. Magnusson, 2003. Canadian consumers willingness-to-pay for pesticide free food products: An ordered probit analysist. Int. Food Agribus. Manage. Rev., 6: 13-30.
Davis, A., A.J. Titterington and C. Cochrane, 1995. Who buys organic food: A profile of the purchasers of organic food in Northern Ireland. Br. Food J., 97: 17-23.

Dipeolu, A.O., B.B. Philip, I.O.O. Aiyelaagbe, S.O. Akinbode and T.A. Adedokun, 2009. Consumer awareness and willingness to pay for organic vegetables in S.W. Nigeria. Asian Journal of Food and Agro-Industry, Special Issue, S57-S65.

Du Toit, L. and S. Crafford, 2003. Belief and purchasing practices of Cape Town consumers regarding organically produced food. J. Family Ecol. Consumer Sci., 31: 1-11.

Engel, W., 2008. Determinants of consumer willingness to pay for organic food in South Africa. University of Pretoria, Faculty of Natural and Agricultural Sciences Department of Agricultural Economics, Degre of Minst Agrar, Pretoria, South Africa.

Fu, T.T., J.T. Liu and J.K. Hammitt, 1999. Consumer willingness to pay for low-pesticide fresh produce in Taiwan. J. Agric. Econ., 50: 220-233.

Govindasamy, R. and J. Italia, 1999. Prediciting willingness to pay a premium for organically grown fresh produce. J. Food Distribution Res., 30: 44-53.

Green, W.H., 2000. Econometric Analysis. 4th Edn., Prentice Hall, Gujarati, Damodar.

Greenan, K., P. Humphreys and R. McLvor, 1997. The green initiative: Improving quality and competitiveness. Eur. Bus. Rev., 97: 208-214.

Hanemann, M., 1984. Welfare evaluations in contingent valuation experiments with discrete responses. Am. J. Agric. Econ., 66: 332-341.

Kalogeras, N., S. Valchovska, G. Baourakis and P. Kalaitzis, 2009. Dutch consumers willingness to pay for organic olive oil. J. Int. Food Agribus. Market., 21: $286-311$.

Lacaze, V., E. Rodriguez and B. Lupin, 2009. Risks perceptions and willingness-to-pay for organic fresh chicken in Argentina. Proceedings of the International Association of Agricultural Economists Conference, Aug. 16-22, Beijing, China, pp: 16-16.

Maddala, G.S., 1983. Limited Dependent and Qualitative Variables in Econometrics. Cambridge University Press, Cambridge.

Senturk, I., 2009. Willingness to pay for genetically modified foods in Turkey: An ordered probit analysis. Empirical Econ. Lett., 8: 431-438.

Shaharudin, M.R., J.J. Pani, S.W. Mansor and S.J. Elias, 2010. Factors affecting purchase intention of organic food in Malaysia's Kedah State. Cross Cult. Commun., 6: 105-116. 